\title{
Broadband RCS Reduction of Antenna with AMC Using Gradually Concentric Ring Arrangement
}

\author{
Fuwei Wang, Yuhui Ren, and Ke Li \\ School of Information Technology, Northwest University, Xi'an, Shaanxi 710127, China \\ Correspondence should be addressed to Fuwei Wang; wfwraul@163.com
}

Received 5 August 2017; Revised 9 October 2017; Accepted 29 October 2017; Published 4 December 2017

Academic Editor: María Elena de Cos Gómez

Copyright (C) 2017 Fuwei Wang et al. This is an open access article distributed under the Creative Commons Attribution License, which permits unrestricted use, distribution, and reproduction in any medium, provided the original work is properly cited.

\begin{abstract}
This paper proposes a new method to the broadband RCS reduction with the artificial magnetic conductor (AMC) surfaces. The AMC surfaces can introduce a zero-degree reflection phase shift to incident waves. The phase difference between the antenna and AMC structures is $180^{\circ}$. Therefore, the AMC structures can be used to achieve RCS reduction. However, the bandwidth of zero-degree reflection phase of AMC structures is very narrow. In light of this, a novel gradually concentric ring arrangement AMC (GCRA-AMC) which can be applied to achieve the broadband RCS reduction is presented. The simulated and measured results show that the radiation performance of antennas is preserved when the GCRA-AMC is used. The RCS of the antenna with GCRA-AMC has been considerably reduced in a broad frequency band. The largest RCS reduction is more than $17 \mathrm{~dB}$.
\end{abstract}

\section{Introduction}

With detection and stealth technology develops rapidly, radar cross section (RCS) reduction has received a lot of attention to different applications. As a special scattering object, the antenna is a major potential source of stealth objects. The RCS reduction of antenna must preserve the basic radiation properties. Therefore, it is very difficult to achieve the RCS reduction of the antenna without deteriorating the radiation properties. To alleviate this difficulty, some ways to reduce the RCS are proposed, such as shaping, coating, slot loading, and probe loading [1-4]. Furthermore, many new materials are applied to the RCS reduction of antenna, such as the electromagnetic bandgap (EBG) structures which have been widely studied for their behavior as AMC [5-7]. The phase difference between the antenna and AMC structures is $180^{\circ}$, and the AMC structures can be used to RCS reduction purposes. Two reflected waves can be completely canceled each other due to the $180^{\circ}$ phase difference.

Nowadays, many EBG and AMC structures are reported about RCS reduction. For example, [8] is the earliest journal paper that teaches the combined use of AMCs and PECs to provide a reflected wave from the AMC that is ideally 180 degrees out of phase with the reflected wave from a metal surface. In [9], the proposed chessboard-like geometries PEC-AMC has good low-RCS feature. In [10], the EBG is applied to the ridged waveguide slot antenna array. After that, the EBG is used to the RCS reduction of the patch array antenna [11]. However, these methods and applications are limited to a narrow band. Currently, there is no specific method for RCS reduction in a broadband by AMC structure.

In practice, the reflection phase of an AMC crosses zero at just one frequency (for one resonant mode). The useful bandwidth of the AMC is generally defined from the frequency point at $+90^{\circ}$ to the one at $-90^{\circ}$. The bandwidth of the RCS reduction is also limited in this frequency band. Therefore, the research on the bandwidth of AMC is very important to the RCS reduction.

As we have known, the characteristics of the AMC (such as central frequency, bandwidth) will be changed by adjusting the equivalent capacitance, resistance, or inductance. Therefore, the configuration of AMC is rearranged, and a nonperiodic AMC structure of a gradually concentric ring arrangement is proposed in this paper. This arrangement of the new AMC makes the equivalent capacitance linearly varies. The bandwidth of AMC by this new arrangement has increased compared with the original arrangement. In 


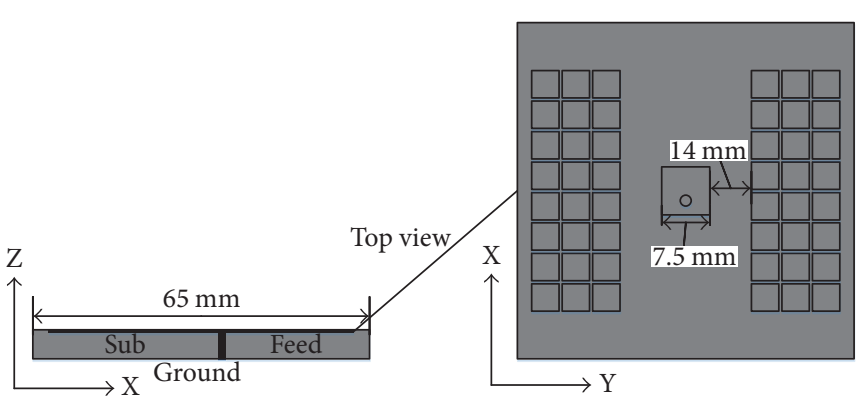

(a) Original AMC

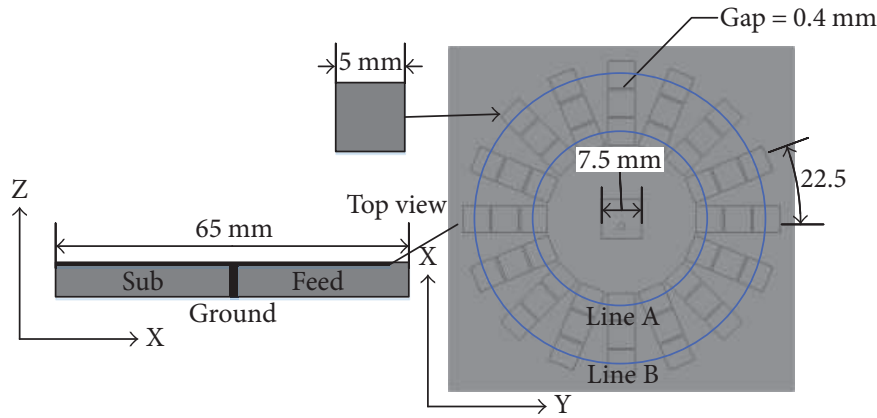

(b) GCRA-AMC

FIgURE 1: The configuration of the antenna with AMC.

this paper, a novel gradually concentric ring arrangement AMC (GCRA-AMC) is presented, and it can be employed to achieve the broadband RCS reduction of microstrip antenna. The simulated and measured results show that the radiation performance of antennas is preserved when the GCRA-AMC is used. The RCS of the antenna has been considerably reduced in a broadband.

\section{Design of the Gradually Concentric Ring Arrangement AMC}

Figure 1(a) shows the method of the original AMC applied to the RCS reduction of microstrip antenna which is taken at $8.4 \mathrm{GHz}$. For the broadband RCS reduction of the microstrip antenna, a nonperiodic AMC structure of a gradually concentric ring arrangement is designed. The configuration of the antenna with GCRA-AMC is shown in Figure 1(b). Microstrip patches are printed on $2 \mathrm{~mm}$ thick FR4 substrates, the dielectric constant of the substrates is 4.4 , and the loss tangent is 0.02 .

This arrangement of the GCRA-AMC makes the equivalent capacitance linearly varies. So, on the surface of the antenna, the reflection phase is inconsistent. Figure 2 shows the simulated reflection phase of the AMC with infinite units, $3 \times 8$ units, respectively. Figure 2 also shows the average value of reflection phase in line $\mathrm{A}$ and line $\mathrm{B}$. Lines $\mathrm{A}$ and $\mathrm{B}$ are shown in Figure 1(b).

In order to investigate the influence of parameters on RCS reduction, a series of parameter analyses is proposed. The simulations are implemented using the analysis software HFSS 13 by Ansys, which is based on the finite element method (FEM) algorithm. First, the number of the legs $N$ has been changed with the other parameters fixed. The "leg" is identifying a radial line of three patches in their GCRA-AMC. It can be seen from Figure 3(a) that with the decrease of $N$, the resonant frequency shifts to a higher frequency and the bandwidth of the RCS reduction narrows down. Then, the gap $g$ has been investigated. In Figure 3(b), we can see that the bandwidth of the RCS reduction is broadening and the RCS reduction is getting worse with the decrease of $g$. To obtain a relatively high and stable GCRA$\mathrm{AMC}$ over the operation frequency band, the values of the parameters are finally determined as given in Figure 1. The

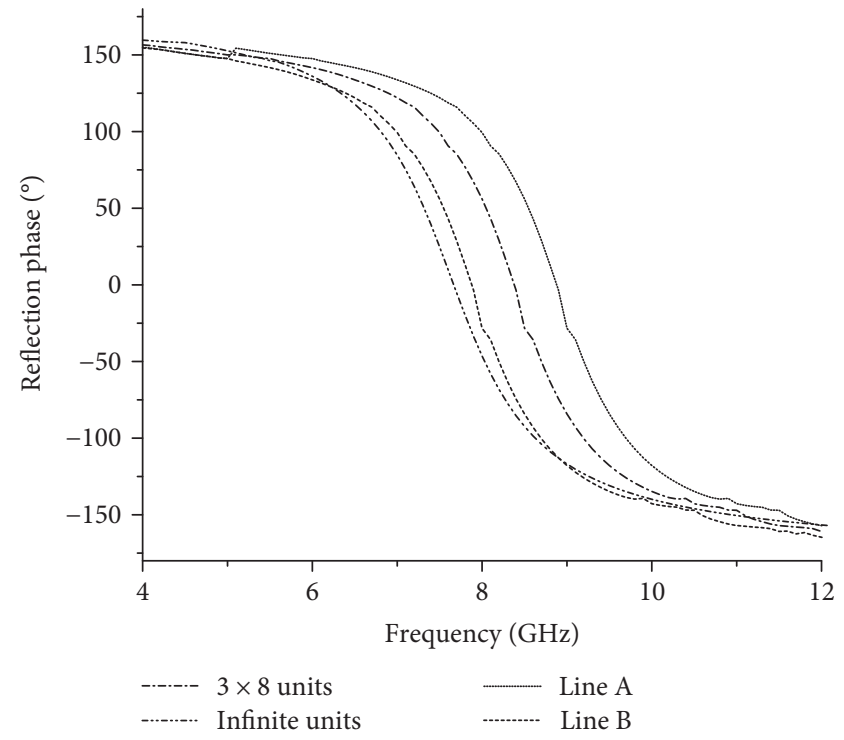

FIGURE 2: The simulated reflection phase.

photograph of antenna with original AMC and GCRAAMC is shown in Figure 4.

As mentioned above, the microstrip antenna with GCRA-AMC is fabricated. The comparison of the monostatic RCS of the checkerboard AMC and the microstrip antenna with original AMC and GCRA-AMC is shown in Figure 5. The configuration of the checkerboard AMC is shown in Figure 6. The incident wave is perpendicular to the ground plane of the antenna. The incident wave is $\varphi$ polarization. Generally speaking, the microstrip antenna RCS at broadside is dominated by the ground plane. Their RCS reduction method is used to reduce the broadside reflection from the ground plane. As shown in Figure 5, $-15 \mathrm{~dB}$ bandwidth of the antenna RCS reduction with GCRA-AMC is broader than the checkerboard AMC and the original one. In order to demonstrate the effectiveness of this method, the radiation performances of antenna with and without GCRA-AMC are evaluated. Figure 7 shows the measured $S_{11}$ of the antenna with and without GCRA-AMC. The central frequency is taken at $8.4 \mathrm{GHz}$, and the accurate central frequency of microstrip antenna with and without GCRAAMC is basically consistent. 


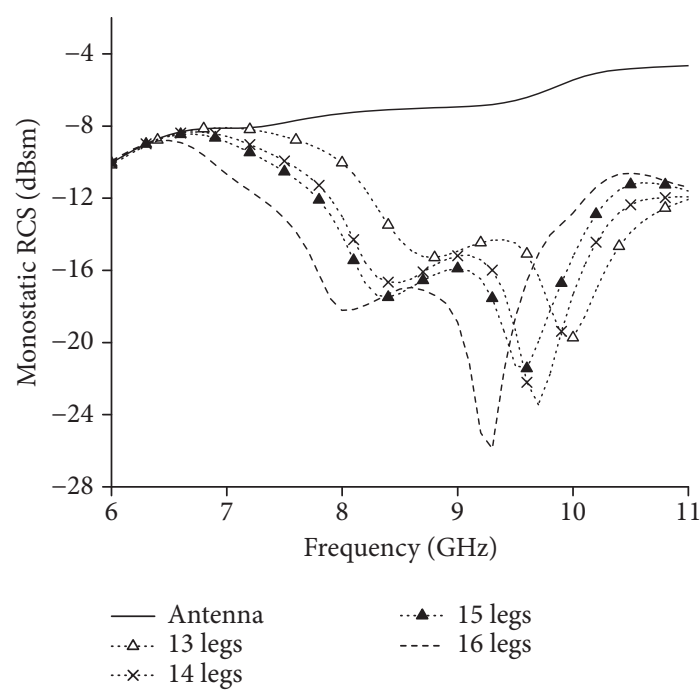

(a) The case of different $N$
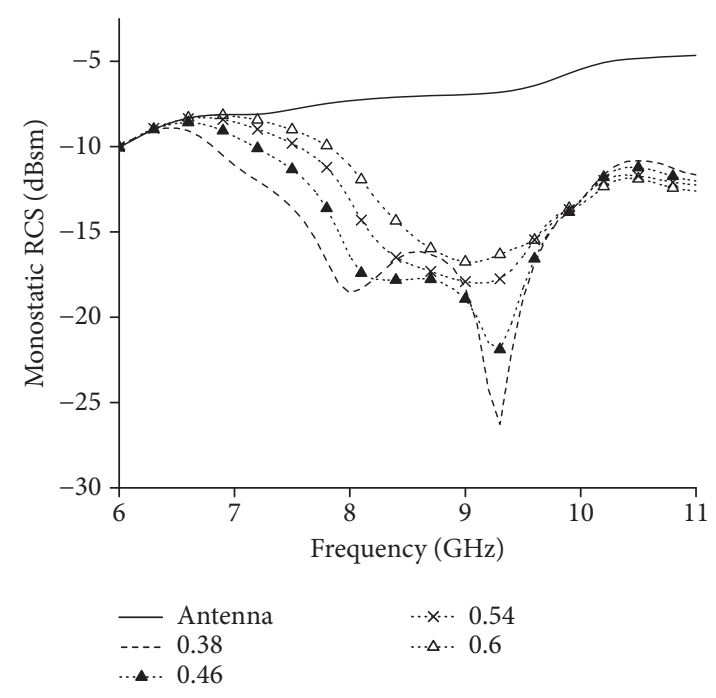

(b) The case of different $g$

FIGURE 3: The monostatic RCS of the antenna for the case of different parameters.

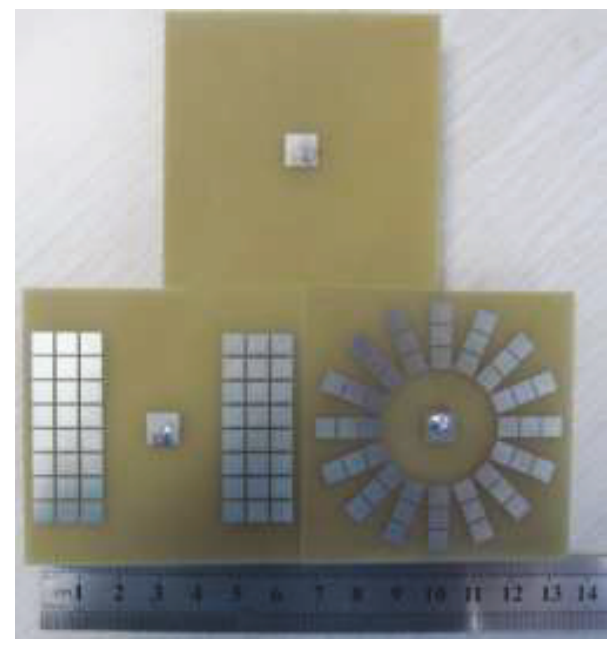

FIGURE 4: The photograph of antenna with original AMC and GCRA-AMC.

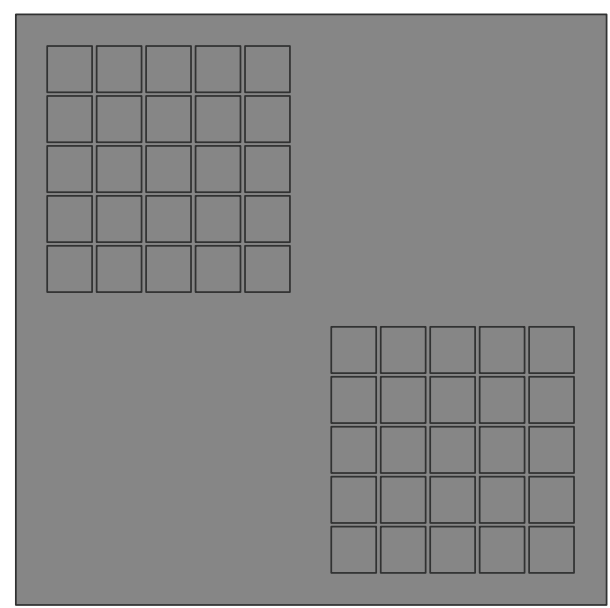

FIgURE 5: The monostatic RCS of the antenna.

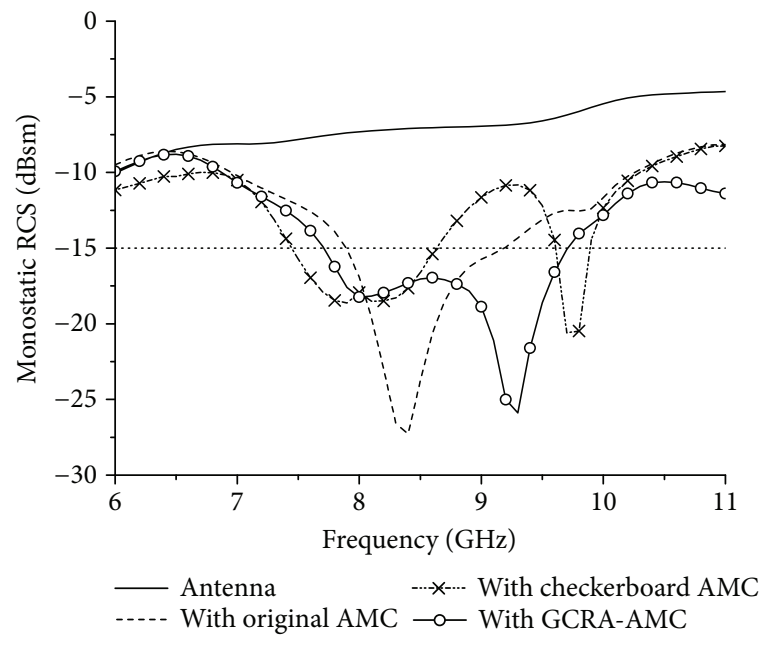

FIgure 6: The configuration of the checkerboard AMC.

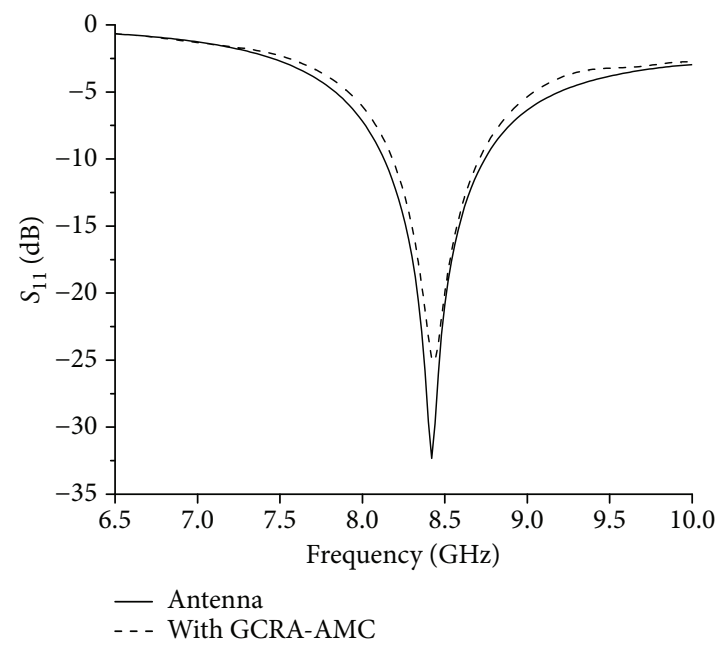

FIGURE 7: The measured $S_{11}$ of the antenna. 


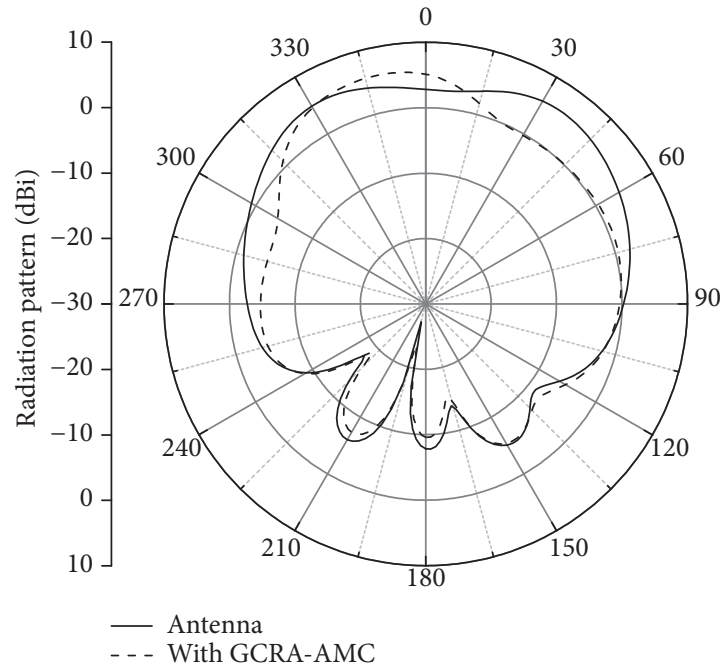

(a) xoz-plane

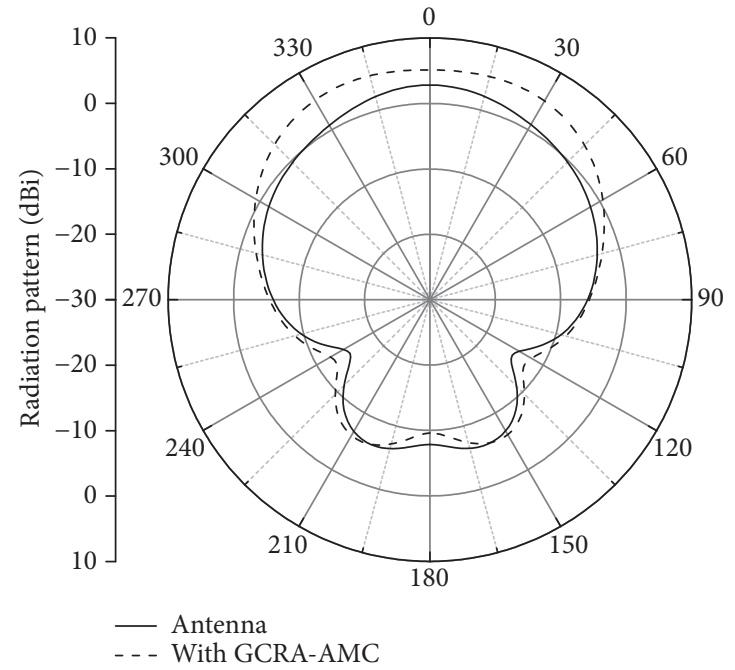

(b) yoz-plane

FIGURE 8: The comparison of the radiation patterns of the microstrip antenna with and without GCRA-AMC.

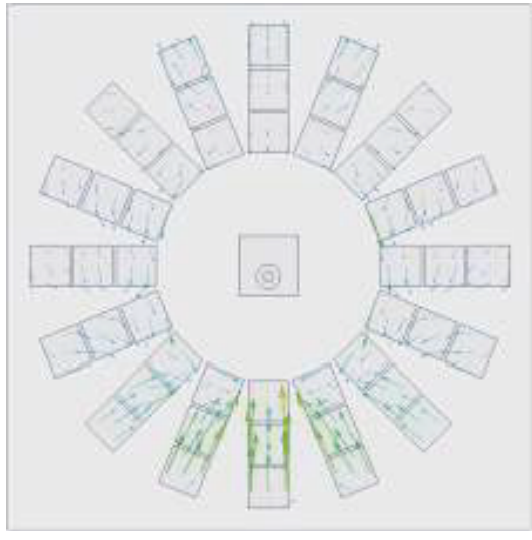

(a) Excited by a coaxial line

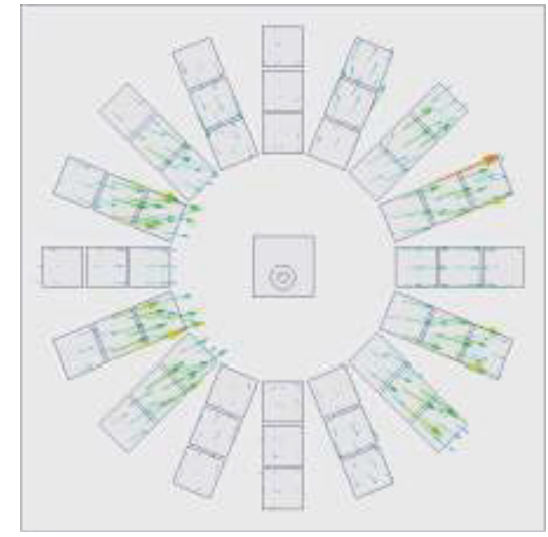

(b) Illuminated by an incident plane wave

FIgURE 9: The surface current of the AMC patch.

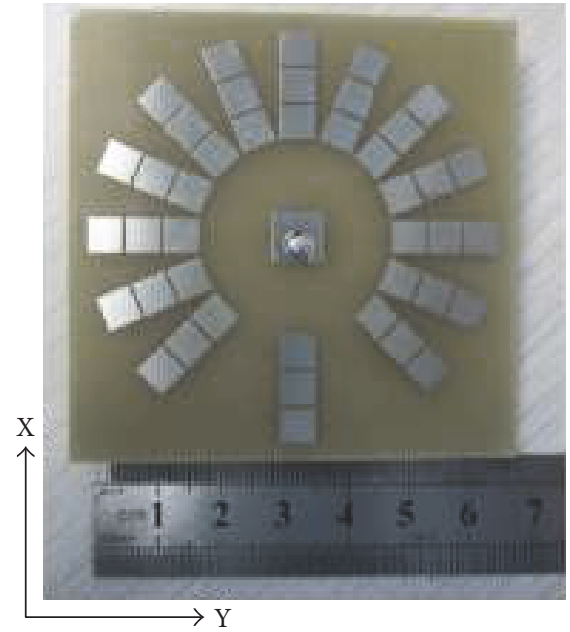

FIGURE 10: The configuration and photograph of antenna with final GCRA-AMC.

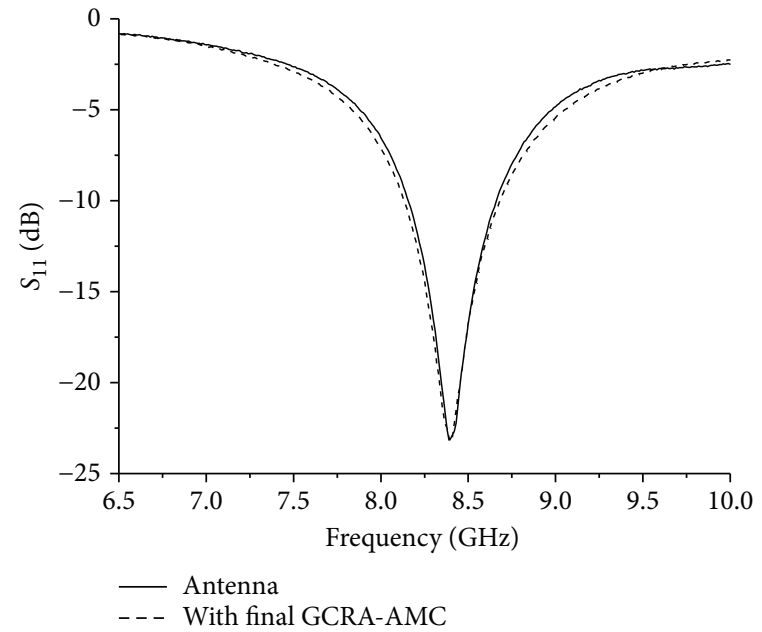

FIgURE 11: The measured $S_{11}$ of microstrip antenna with and without final GCRA-AMC. 


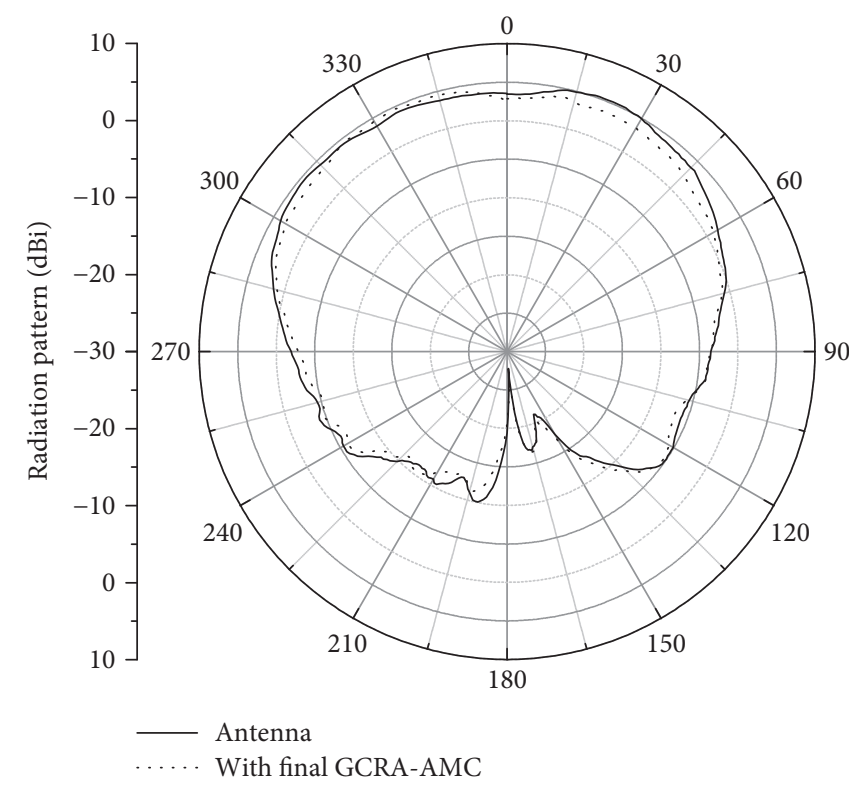

(a) xoz-plane

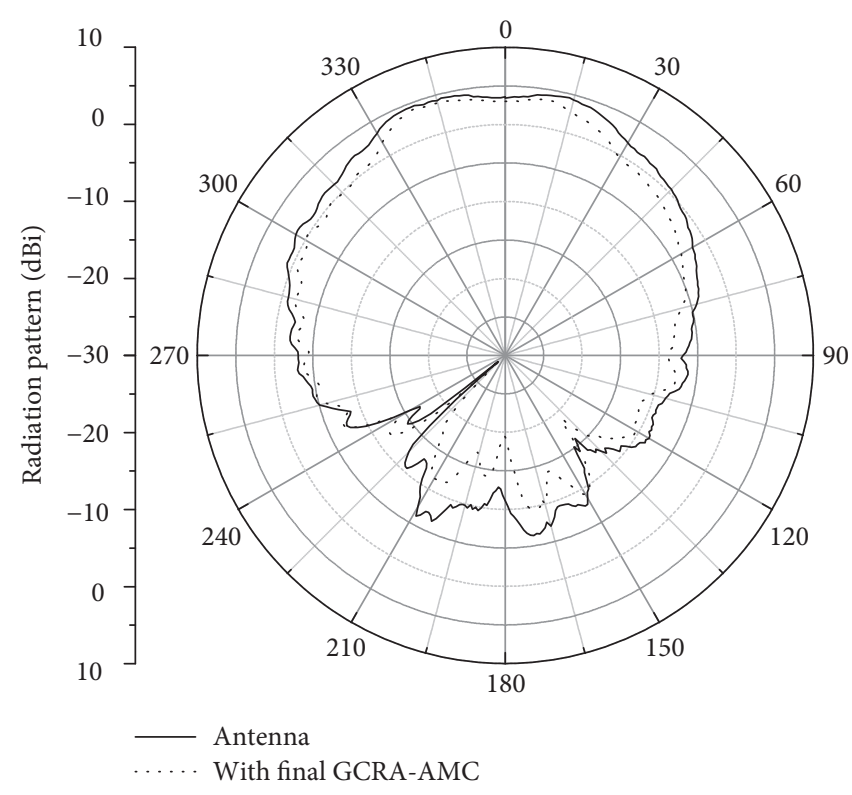

(b) yoz-plane

FIGURE 12: The radiation patterns of the microstrip antenna with and without final GCRA-AMC.

Figure 8 shows the comparison of simulated radiation patterns of the antenna with and without GCRA-AMC in the xoz-plane (E-plane) and yoz-plane (H-plane). As shown in Figure 8, the radiation patterns of the microstrip antenna are obviously deteriorated. Therefore, the GCRA configuration is needed to improve.

The surface current of the AMC patch in two different cases are analyzed, respectively. As shown in Figure 9, one case is that the antenna is excited by a coaxial line, and the other one is that the whole structure is illuminated by an incident plane wave. The incident wave is $\varphi$-polarization. It can be seen that when the antenna is excited by a coaxial line, the current of three legs at the bottom of the antenna are very large. When the whole structure is illuminated by an incident plane wave, the surface current of these three legs are very weak. It shows that these three legs greatly influence on the radiation performance of the antenna and it did not bring a greater impact on the scattering of the antenna. Therefore, it is possible to remove two of these three legs to reduce the effect on the radiation performance of the antenna.

The prototype of the designed antenna with final GCRA-AMC has been manufactured and tested. The configuration and photograph of antenna with final GCRAAMC are shown in Figure 10. Its characteristics are measured by using a vector network analyzer and a fully automated anechoic chamber. Figure 11 shows the measured $S_{11}$ of the antenna with and without GCRA-AMC. The dotted line indicates the antenna with GCRA-AMC, and the continuous line is that of the original antenna. It is seen that the $S_{11}$ of the antenna with and without GCRA-AMC has a good agreement. The comparison of the measured radiation pattern $(8.4 \mathrm{GHz})$ of the antenna is shown in Figure 12. Figures 12(a) and 12(b) show the radiation pattern in the xoz-plane (E-plane) and yoz-plane (H-plane), respectively. At the working frequency, the gain of the antenna with

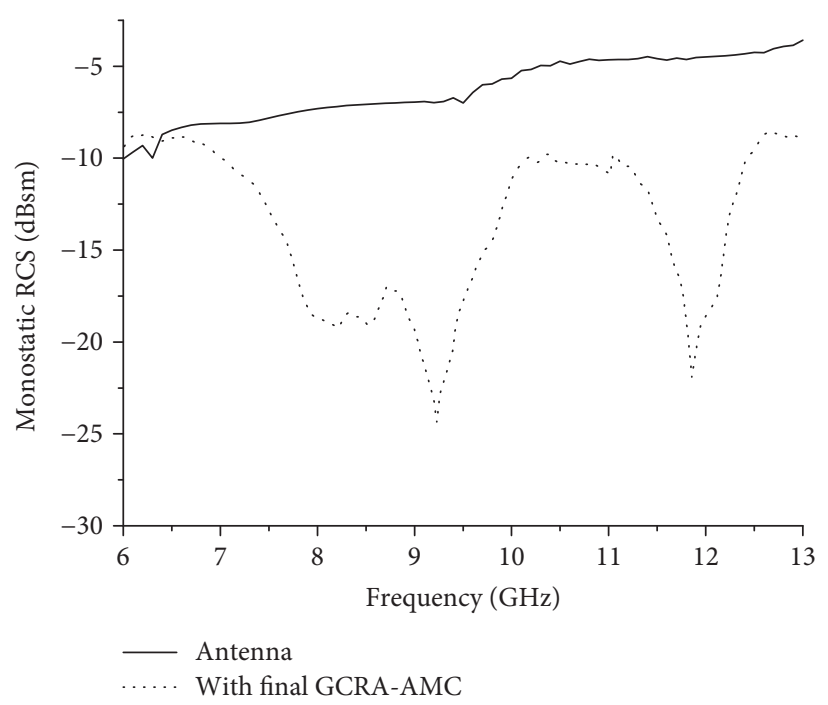

FIgURE 13: The monostatic RCS of the microstrip antenna with and without final GCRA-AMC.

GCRA-AMC is lower than that of the antenna without GCRA-AMC, with the largest gain degradation being $0.6 \mathrm{~dB}$. A certain asymmetry of the pattern is mainly due to the error of measurement. The simulated and measured results demonstrate that the radiation characteristics of the antenna with GCRA-AMC are preserved.

Figure 13 shows the comparison of the measured monostatic RCS of the microstrip antenna with and without GCRA-AMC. The incident wave is perpendicular to the ground plane of the antenna, and the incident wave is $\varphi$-polarization. The microstrip antenna is terminated with a matching load. From Figure 5, it can be seen that there is considerable broadband RCS reduction of the antenna with 


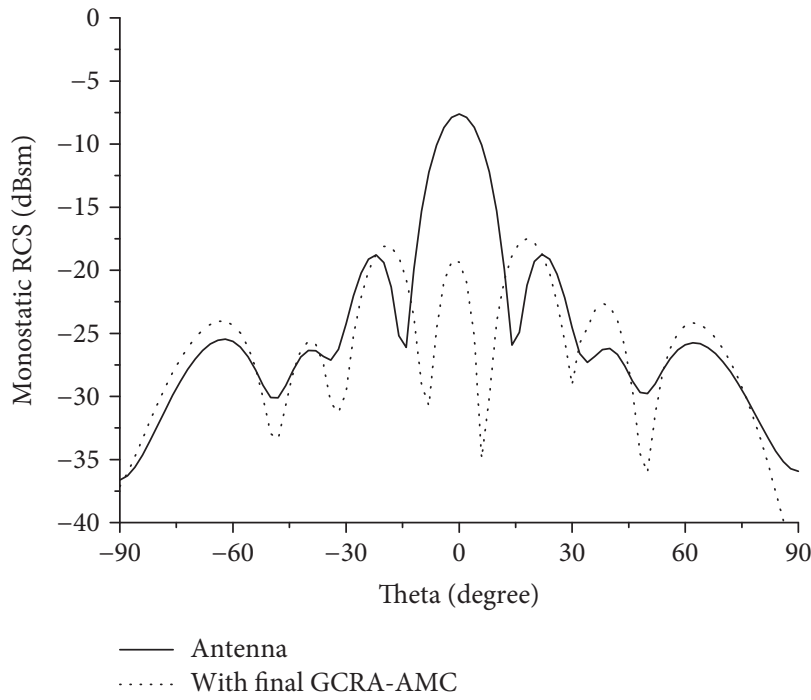

(a) $x o z$-plane

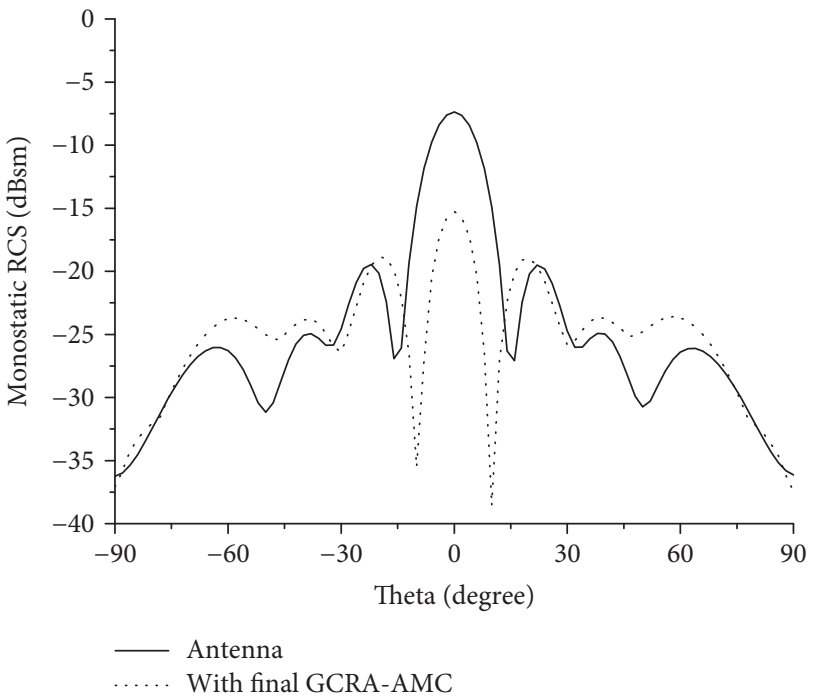

(b) yoz-plane

FIGURE 14: The monostatic RCS of the microstrip antenna with and without final GCRA-AMC under different incident angles.

GCRA-AMC, and the largest reduction is more than $17 \mathrm{~dB}$ at 9.3 GHz. The microstrip antenna with GCRA-AMC has a low RCS characteristic in a wideband.

The analysis of the simulated monostatic RCS reduction under different incident angles is proposed in Figure 14. The incident wave is $\varphi$-polarization. As shown in Figure 14, noticeable RCS reduction of the microstrip antenna with final GCRA-AMC is achieved within the angles from $-20^{\circ}$ to $+20^{\circ}$ in two planes. Therefore, the monostatic RCS of the microstrip antenna which used final GCRA-AMC structure can be reduced.

\section{Conclusion}

A novel gradually concentric ring arrangement AMC (GCRA-AMC) has been proposed to the broadband RCS reduction of antenna. Two legs are removed to reduce the effect on the radiation performance of the antenna. The experimental results show that the radiation performance of microstrip antenna is preserved. The RCS of the antenna with a GCRA-AMC can be reduced in a broadband, and the largest reduction is more than $17 \mathrm{~dB}$. The microstrip antenna with GCRA-AMC has a low RCS characteristic in a broadband.

\section{Conflicts of Interest}

The authors declare that there is no conflict of interest regarding the publication of this paper.

\section{Acknowledgments}

This article is supported by the National Natural Science Funds of China (no. 61501372).

\section{References}

[1] A. Edalati and K. Sarabandi, "Wideband, wide angle, polarization independent RCS reduction using nonabsorptive miniaturized-element frequency selective surfaces," IEEE Transactions on Antennas and Propagation, vol. 62, no. 2, pp. 747-754, 2014.

[2] F. Wang, W. Jiang, T. Hong, H. Xue, S. Gong, and Y. Zhang, "Radar cross section reduction of wideband antenna with a novel wideband radar absorbing materials," IET Microwaves, Antennas \& Propagation, vol. 8, no. 7, pp. 491-497, 2014.

[3] W. Jiang, T. Hong, and S. X. Gong, "Research on the scattering characteristics and the RCS reduction of circularly polarized microstrip antenna," International Journal of Antenna and Propagation, vol. 2013, Article ID 735847, 9 pages, 2013.

[4] F. Wang, T. Hong, and S. Gong, "Left-handed material superstrate applied to the RCS reduction of microstrip antenna," Journal of Electromagnetic Waves and Applications, vol. 30, no. 11, pp. 1428-1439, 2016.

[5] W. Hu, R. N. Lian, Z. Y. Tang, and Y. Z. Yin, "Wideband, low-profile, dual-polarized slot antenna with an AMC surface for wireless communications," International Journal of Antenna and Propagation, vol. 2016, Article ID 7641382, 8 pages, 2016.

[6] L. Zhao, D. Yang, H. Tian, Y. Ji, and K. Xu, "A pole and AMC point matching method for the synthesis of Hsf-Uc-EBG structure with simultaneous AMC and EBG properties," Progress in Electromagnetics Research, vol. 133, pp. 137-157, 2013.

[7] F. Wang, S. Gong, and S. Zhang, "Broadband RCS reduction of antenna with AMC," in 2015 IEEE 4th Asia-Pacific Conference on Antennas and Propagation (APCAP), pp. 606-607, Kuta, Indonesia, 2015.

[8] M. Paquay, J. C. Iriarte, I. Ederra, R. Gonzalo, and P. de Maagt, "Thin AMC structure for radar cross-section reduction," IEEE Transactions on Antennas and Propagation, vol. 55, no. 12, pp. 3630-3638, 2007.

[9] M. E. de Cos, Y. Álvarez, and F. Las-Heras, "RCS reduction using a combination of artificial magnetic conductors," in 
Proceedings of the 5th European Conference on Antennas and Propagation (EUCAP), pp. 1336-1340, Rome, Italy, 2011.

[10] Y. Q. Li, H. Zhang, F. YQ, and N. C. Yuan, "RCS reduction of ridged waveguide slot antenna array using EBG radar absorbing material," IEEE Antennas and Wireless Propagation Letters, vol. 7, pp. 473-476, 2008.

[11] J. Zhang, J. Wang, M. Chen, and Z. Zhang, "RCS reduction of patch array antenna by electromagnetic band-gap structure," IEEE Antennas and Wireless Propagation Letters, vol. 11, pp. 1048-1051, 2012. 


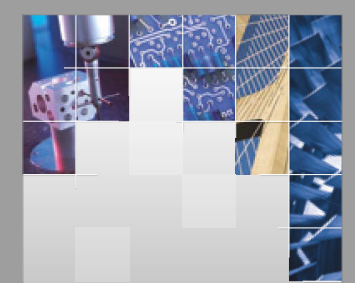

\section{Enfincering}
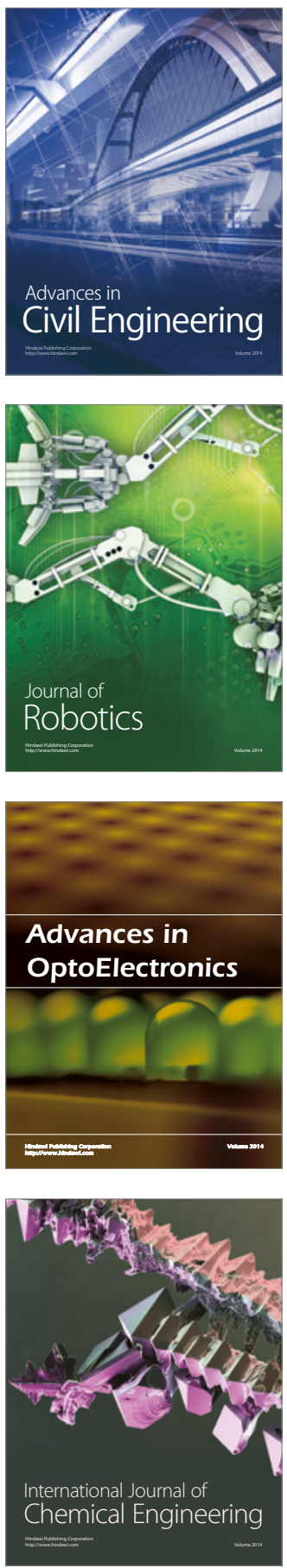

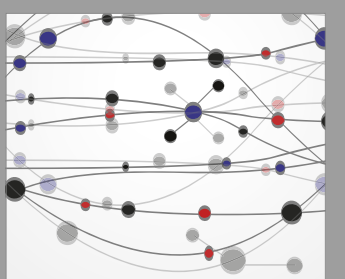

The Scientific World Journal

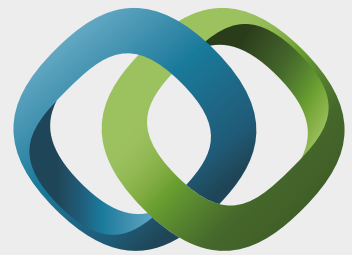

\section{Hindawi}

Submit your manuscripts at

https://www.hindawi.com
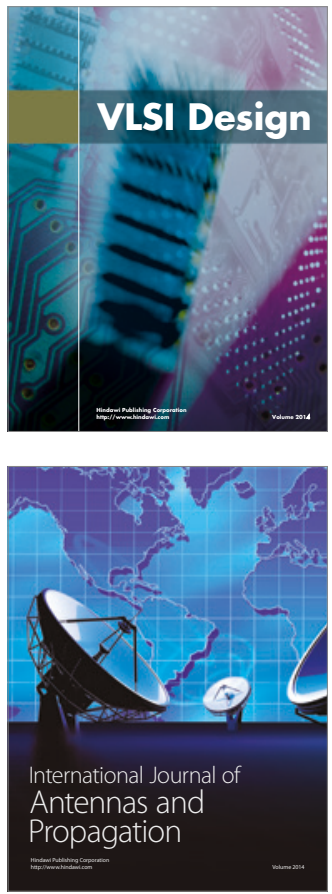

\section{Rotating}

Machinery
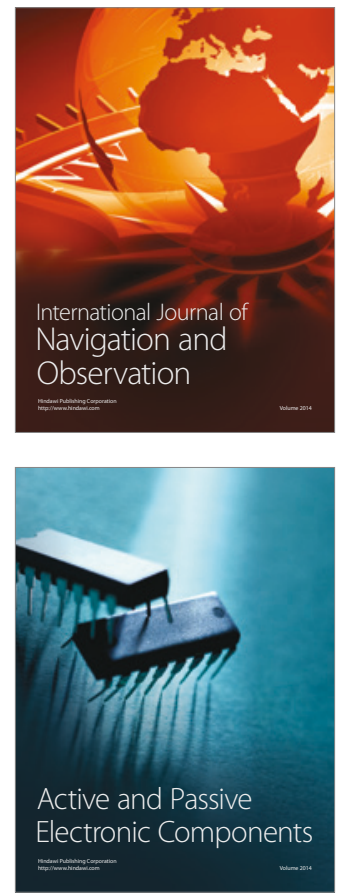
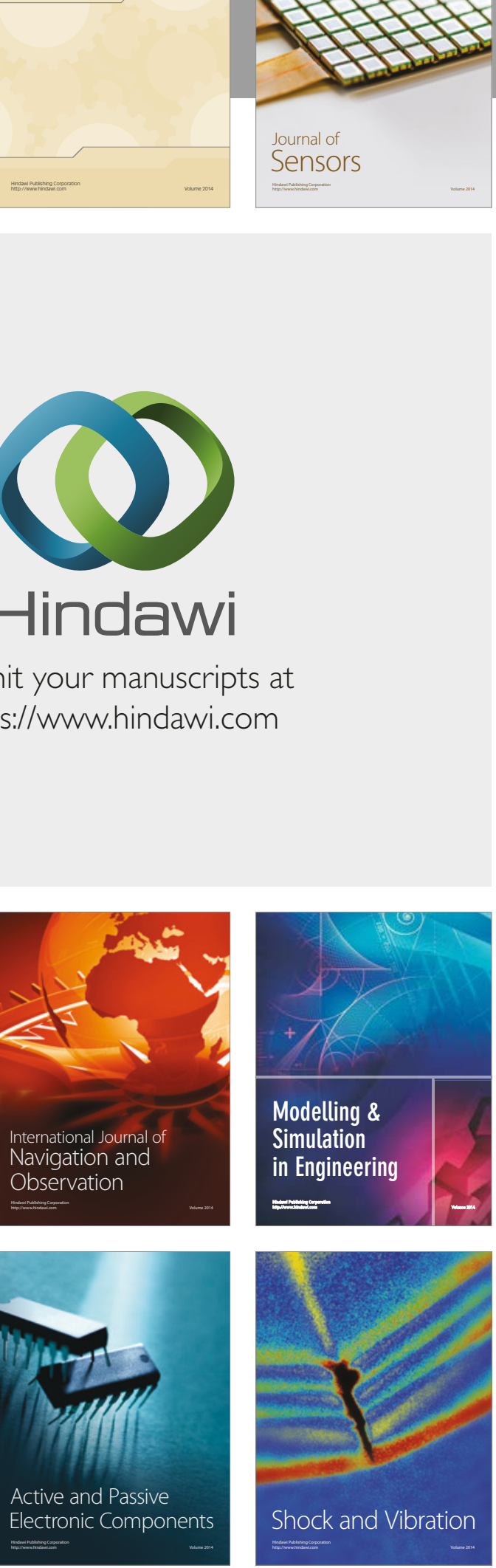
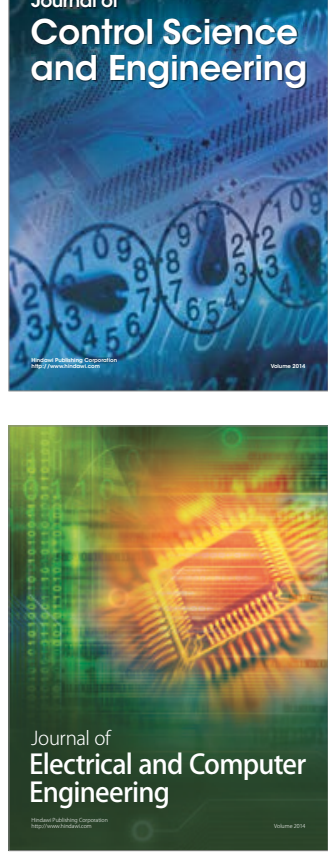

Distributed

Journal of

Control Science

and Engineering
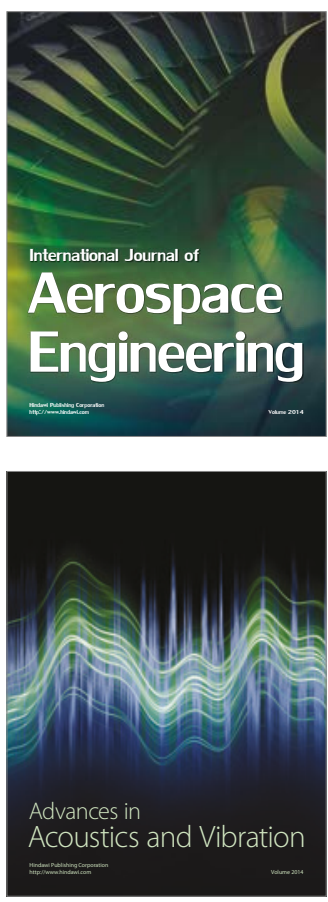

Sensor Networks 